\title{
Inflammation-mediating cytokine response to acute handcycling exercise with/without functional electrical stimulation-evoked lower-limb cycling
}

\author{
Thomas A. W. Paulson, MSc; ${ }^{*}$ Nicolette C. Bishop, PhD; Brett M. Smith, PhD; Victoria L. Goosey-Tolfrey, PhD \\ School of Sport, Exercise and Health Sciences, Loughborough University, Loughborough, United Kingdom
}

\begin{abstract}
This feasibility study compared the plasma inflammation-mediating cytokine response to an acute bout of handcycling $(\mathrm{HC})$ with and without the addition of functional electrical stimulation (FES)-evoked lower-limb cycling. On two separate occasions, five recreationally active, communitybased participants with motor complete paraplegia (thoracic 57) performed 30 min $\mathrm{HC}$ and hybrid exercise (HYB) at a fixed power output. Venous blood samples were collected at rest, immediately postexercise, $1 \mathrm{~h}$ postexercise $($ post +1$)$ and $2 \mathrm{~h}$ postexercise (post+2). Plasma interleukin (IL)-6, IL-10, IL-1 receptor antagonist (IL-1ra), adrenaline, and cortisol concentrations were determined via enzyme-linked immunoassay. Plasma IL-6 concentrations were significantly $(p<0.04)$ elevated $(\sim 2.5$-fold $)$ at post +1 and post +2 in HYB only. A small (0.5-fold), nonsignificant $(p>0.05)$ increase in IL-6 was observed at post +1 in $\mathrm{HC}$, with concentrations significantly higher in HYB at post+2 $(p<0.02)$. Plasma IL-1ra was unaffected in both trials. Although not reaching statistical significance $(p=0.15), a \sim 1$-fold increase in IL-10 concentration was seen in HYB at post +2 . In contrast, increases in adrenaline $(p<$ $0.04)$ and cortisol $(p=0.08)$ were observed immediately postexercise in $\mathrm{HC}$ and $\mathrm{HYB}$. Initial findings suggest paralyzed skeletal muscle releases IL-6 in response to FES-evoked contractions. HYB may provide a greater anti-inflammatory potential in individuals with a thoracic spinal cord injury compared with $\mathrm{HC}$ alone.
\end{abstract}

Key words: anti-inflammatory, cardiovascular disease, health, immunoendocrine, myokine, physical activity, skeletal muscle, spinal cord injury, stress hormones, training.

\section{INTRODUCTION}

Lower-limb paralysis and immobilization following a spinal cord injury (SCI) result in the increase in relative adiposity and the atrophy of skeletal muscle [1]. Persons with an SCI are exposed to elevated factors for chronic disease, including altered metabolic regulation, physical inactivity, and chronic inflammation [2]. Cardiovascular mortality rates are therefore higher than those for nonSCI groups, with the onset of disease occurring earlier in life [2]. Following release from contracting skeletal

\footnotetext{
Abbreviations: $\mathrm{ANOVA}=$ analysis of variance, $\mathrm{BLa}^{-}=$blood lactate concentration, $\mathrm{CVD}=$ cardiovascular disease, $\mathrm{FES}=$ functional electrical stimulation, $\mathrm{HC}=$ handcycling, $\mathrm{HPA}=$ hypothalamic-pituitary-adrenal, $\mathrm{HR}=$ heart rate, $\mathrm{HYB}=$ hybrid exercise, IL = interleukin, IL-1 ra = interleukin-1 receptor antagonist, $\mathrm{PO}=$ power output, $\mathrm{PO}_{\text {peak }}=$ peak aerobic power, post $+1=1 \mathrm{~h}$ postexercise, post $+2=2 \mathrm{~h}$ postexercise, $\mathrm{RER}=$ respiratory exchange ratio, $\mathrm{RPE}=$ rating of perceived exertion, $\mathrm{RPE}_{\mathrm{c}}=$ central RPE, $\mathrm{RPE}_{\mathrm{o}}=$ overall $\mathrm{RPE}, \mathrm{RPE}_{\mathrm{p}}=$ peripheral RPE, SCI = spinal cord injury, $\mathrm{SNS}=$ sympathetic nervous system, $\mathrm{TNF}=$ tumor necrosis factor, $\mathrm{VO}_{2}=$ oxygen uptake, $\dot{\mathrm{VO}}_{2 \text { peak }}=$ peak oxygen uptake.

*Address all correspondence to Thomas A. W. Paulson, MSc; The Peter Harrison Centre for Disability Sport, School of Sport, Exercise and Health Sciences, Loughborough University, Loughborough, Leicestershire, LE11 3TU, England, UK; +44 (0)-1509-226385; fax: +44 (0)-1509226301. Email: T.Paulson@lboro.ac.uk
} http://dx.doi.org/10.1682/JRRD.2013.08.0184 
muscle, the myokine interleukin (IL)-6 is associated with subsequent elevations in plasma concentrations of the anti-inflammatory cytokines IL-1 receptor antagonist (IL-1ra), IL-10, and the soluble tumor necrosis factor (TNF) receptors [3-4]. It is proposed that this transient anti-inflammatory environment may contribute to the downregulation of proinflammatory pathways driving the development of insulin resistance and atherosclerotic plaque [5]. Subsequently, participation in regular exercise following an SCI may provide a therapeutic countermeasure to chronic inflammation and reduce the longterm risk of chronic diseases, including cardiovascular disease (CVD) and type 2 diabetes [6].

As a result of the lower-limb paralysis, exercise training in people with an SCI typically involves upperbody activities (e.g., handcycling [HC], wheelchair propulsion, arm-crank ergometry) [7-8]. In non-SCI and thoracic level SCI groups, elevations in plasma IL-6 concentrations have been observed following moderate intensity, submaximal arm-crank ergometry [9-10]; wheelchair basketball performance [11]; and maximal, treadmill-based wheelchair propulsion [12]. To date, the anti-inflammatory cytokine response to upper-limb exercise remains unclear [12]. Compared with manual wheelchair propulsion, $\mathrm{HC}$ provides a more efficient mode of outdoor mobility that reduces mechanical strain on the upper limb [13]. The relatively low physical strain, range of accessible equipment, and beneficial effects on physical capacity make HC a popular exercise mode for rehabilitation practitioners and sports competitors alike [14]. No work to date has examined the circulating plasma cytokine response to an acute bout of $\mathrm{HC}$ exercise.

The application of electrical currents to restore some functional movement, including standing and cycling, in paralyzed skeletal muscle is termed functional electrical stimulation (FES) [15]. Intensive FES-evoked cycling and resistance training improves metabolic health while increasing the size and strength of lower-limb lean body mass [15-16]. The addition of FES-evoked cycling to concurrent upper-limb exercise, termed hybrid exercise (HYB), has been shown to elicit greater cardiorespiratory stress than arm exercise alone [17]. Via the activation of a larger muscle mass, HYB may provide a more effective method for improving cardiorespiratory fitness and reducing risk factors for CVD than traditional upper-limb exercise modes [18]. It is unknown whether the deterioration in skeletal muscle size [19] and alterations in skeletal muscle metabolism [20] observed following lower-limb paralysis will affect the release of IL-6 and the subsequent anti-inflammatory cascade. Similarly, it is unknown whether involuntary FES-evoked contractions can activate intracellular signaling mechanisms responsible for the production and release of the myokine IL- 6 during acute exercise [3-21].

The aim of this feasibility study was therefore to compare the plasma inflammation-mediating cytokine response to an acute bout of $\mathrm{HC}$ with and without the addition of FES-evoked lower-limb cycling. We hypothesized that $30 \mathrm{~min}$ of moderate intensity voluntary $\mathrm{HC}$ would result in a significant IL-6 and anti-inflammatory cytokine response in a group of persons with thoraciclevel SCI. Importantly, this inflammation-mediating cytokine response would be augmented by the addition of FES-evoked lower-limb cycling because of the activation of a greater muscle mass and subsequent greater plasma IL-6 response postexercise.

\section{METHODS}

\section{Participants and Study Design}

Five recreationally active, community-based participants with a motor complete paraplegia volunteered to participate in the study (Table 1). At the time of providing written informed consent, participants were required to be at least $1 \mathrm{yr}$ postinjury. Prior to participating in the experimental trials, each participant was required to have undertaken at least 3 mo supervised FES-evoked training (2-3 sessions per week). All participants had undergone full medical screening by an independent physician prior to undertaking their individual FES-evoked training. Experience with $\mathrm{HC}$ was not a prerequisite for inclusion. Exclusion criteria included the incidence of pressure sores, pacemaker, or lower-limb metal implants and evidence of hypertension or previous dysreflexic responses to FES-evoked exercise. All procedures were approved by the local ethical advisory committee and performed in accordance with the Declaration of Helsinki. The authors certify that all applicable institutional and governmental regulations concerning the ethical use of human volunteers were followed during the course of this research.

The study used a repeated measures design, with participants performing three separate exercise sessions. During the first visit, an HC-only graded exercise test to exhaustion wạs performed to determine peak oxygen uptake $\left(\mathrm{VO}_{2 \text { peak }}\right)$ and peak aerobic power $\left(\mathrm{PO}_{\text {peak }}\right)$. During the second and third visits, participants performed $30 \mathrm{~min}$ of 
Table 1.

Participant characteristics and peak physiological responses.

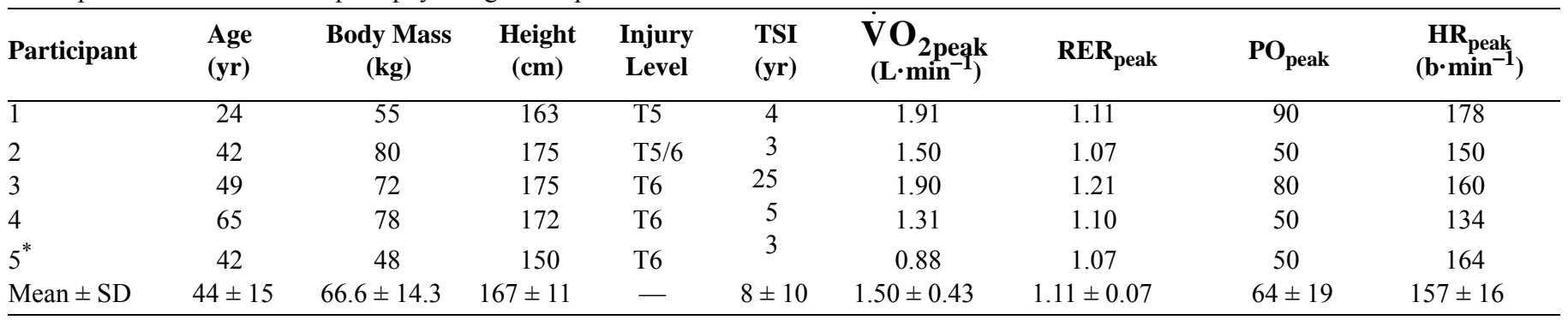

Note: All participants presented motor and sensory complete injury (American Spinal Injury Association impairment scale A).

*Female participant.

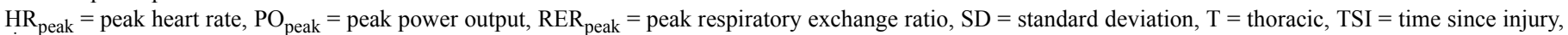
$\mathrm{VO}_{2 \text { peak }}=$ peak oxygen uptake.

HC exercise with and without concurrent lower-limb FESevoked cycling at the same absolute power output $(60 \% \mathrm{HC}$ $\left.\mathrm{PO}_{\text {peak }}\right)$ in a counterbalanced order. Main trials were separated by at least 7 but no more than $14 \mathrm{~d}$.

\section{Instrumentation}

All exercise tests were performed on a commercially available eight-gear hybrid exercise bicycle (Berkelbike BV; St. Michielsgestel, the Netherlands) mounted on a cycle force magnetic flow ergotrainer (T1682, Tacx; Wassenaar, the Netherlands). A deceleration test to calculate rolling resistance was performed prior to each session as described in the manufacturer's operating manual. While in a seated position, participants' feet were strapped to adjustable aluminum ankle-calf supports to prevent movement about the ankle and constrain limb movement to the sagittal plane. The power measured at the front wheel was the result of the combined torque produced about the arm and leg cranks. The bicycle offers voluntary synchronous HC with passive or FESevoked asynchronous leg cycling movements. For FESevoked cycling, an external six-channel stimulator (Impuls, Berkelbike BV) provided electrical stimulation via self-adhesive electrodes (Tens; Nottingham, United Kingdom) placed bilaterally over the neuromuscular points of the quadriceps, hamstring, and gluteus muscles. The stimulator received information about pedal position and crank velocity from the crank encoder to control the cyclic stimulation pattern. The maximum stimulation intensity was $145 \mathrm{~mA}$ with a frequency of $35 \mathrm{~Hz}$. Stimulation intensity could be manually adjusted via $7.5 \mathrm{~mA}$ increments/decrements. Seat angle, seat position, and crank height were individually manipulated and standardized to ensure the crank axle was positioned at shoul- der height and sufficient degree of flexion remained around the knee joint. Tire pressure was set at $60 \mathrm{psi}$ and controlled before each session using a manual tire pump with psi gauge (Topeak sport bike pump; Halfords, United Kingdom).

The Borg 6-20 scale was used to attain participants' differentiated rating of perceived exertion (RPE) throughout the trials. Participants were given standardized instructions detailing the use of the Borg 6-20 scale and the associated verbal anchors at the beginning of each session [22]. To determine central RPE $\left(\mathrm{RPE}_{\mathrm{c}}\right)$, participants were asked to rate their perceived exertion for the heart, lungs, and breathing. To determine peripheral RPE $\left(R_{P} E_{p}\right)$, participants were asked to rate exertion only from the exercising muscle groups and joints. Overall RPE $\left(\mathrm{RPE}_{\mathrm{O}}\right)$ was then reported as the combination of $R_{P} E_{p}$ and $R P E_{c}$. The RPE scale was visible to participants for the duration of each trial.

\section{Data Collection}

\section{Preliminary Measurements and Graded Exercise Test to Exhaustion}

On arrival, participants' body mass was obtained to the nearest $0.1 \mathrm{~kg}$ using double-beam seated scales (Marsden MPWS-300; Rotherham, United Kingdom). Participants rested in a seated position for $15 \mathrm{~min}$ before resting oxygen uptake $\left(\mathrm{VO}_{2}\right)$ was measured for $10 \mathrm{~min}$ using an online, breath by breath respiratory gas analysis system (Cortex metalyser 3B, Cortex; Leipzig, Germany). Resting heart rate (HR) was recorded using radiotelemetry (Polar PE 4000; Kempele, Finland). To allow familiarization with the hybrid cycle and gearing system, all participants performed 10 min unloaded $\mathrm{HC}$ with 
passive leg movements. Following familiarization, a 5 min warm-up was performed at $10 \mathrm{~W}$. The graded exercise test to exhaustion began at a power output (PO) of $10 \mathrm{~W}$ for $2 \mathrm{~min}$. Subsequently, $10 \mathrm{~W}$ increments were added every minute until PO could not be maintained or the participant requested to stop. Because some participants were unable to manually adjust the gearing system, the experimenter altered gearing selection upon request. The highest $30 \mathrm{~s}$ rolling average $\mathrm{VO}_{2}$ value was defined as $\mathrm{VO}_{2 \text { peak }}$. $\mathrm{PO}_{\text {peak }}$ was determined as the highest $\mathrm{PO}$ for a completed stage of the graded exercise test.

\section{Main Experimental Trials}

Handcycling only. Following a 5 min standardized warm-up of $10 \mathrm{~W}, \mathrm{HC}$ exercise was performed at an imposed exercise intensity of 60 percent $\mathrm{PO}_{\text {peak }}$ for $30 \mathrm{~min}$. The participants self-selected their gearing during the first 3 min of exercise. Gearing was subsequently standardized across trials. $\mathrm{VO}_{2}$ and $\mathrm{HR}$ were measured continuously throughout the $30 \mathrm{~min}$ trial. A small capillary blood sample was obtained from the earlobe before exercise and every $10 \mathrm{~min}$ during exercise to determine blood lactate concentration $\left(\mathrm{BLa}^{-}\right)$using a YSI 1500 SPORT Lactate Analyzer (YSI Inc; Yellow Springs, Ohio). The lactate analyzer was calibrated with a lactate standard of $5 \mathrm{mmol} \cdot \mathrm{l}^{-1}$. Differentiated RPE was also recorded every $10 \mathrm{~min}$ as previously described.

Handcycling with concurrent FES-evoked lowerlimb cycling (hybrid exercise). Self-adhesive electrodes were placed bilaterally over the lower limbs as previously described. Low intensity stimulation $(60 \mathrm{~mA})$ was provided during the standardized warm-up. Stimulation amplitude was manually increased $7.5 \mathrm{~mA}$ every $5 \mathrm{~min}$ during the main trial from an initial intensity of $60 \mathrm{~mA}$. An incremental stimulation protocol was employed to negate the premature fatigue of lower-limb muscles and maintain a consistent recruitment of muscle fibers throughout the $30 \mathrm{~min}$ trial. $\mathrm{VO}_{2}, \mathrm{HR}, \mathrm{BLa}^{-}$, and differentiated RPE were recorded as in HC only.

\section{Blood Collection and Analyses}

A $7.5 \mathrm{~mL}$ blood sample was collected before (preexercise), immediately after (postexercise), $1 \mathrm{~h}$ postexercise (post +1 ), and $2 \mathrm{~h}$ postexercise (post +2 ) from an antecubital vein into a $K_{3}$ EDTA vacutainer. Blood samples were refrigerated until the final sample from each participant was collected and then spun down together in a refrigerated $\left(4^{\circ} \mathrm{C}\right)$ centrifuge at $1,500 \mathrm{~g}$ for $10 \mathrm{~min}$. The separated plasma was immediately stored at $-80^{\circ} \mathrm{C}$. Plasma concentrations of IL-6, IL-10, IL-1 ra, cortisol, and adrenaline were determined using quantitative sandwichtype enzyme-linked immunosorbant assay kits (IL-6, IL10, TNF- $\alpha$, IL-1ra: R\&D Systems, Abingdon, United Kingdom; cortisol: DRG Instruments, Marburg, Germany; adrenaline: IBL International, Hamburg, Germany) according to the manufacturers' instructions. All samples were analyzed in duplicate. The within-assay coefficient of variation for the analyses performed were as follows: adrenaline: 2.7 percent, cortisol: 3.6 percent, IL-6: 6.5 percent, IL-10: 8.3 percent, and IL-1ra: 4.3 percent.

\section{Statistical Analysis}

All data were analyzed using the statistical package SPSS for Windows version 20 (IBM Corporation; Armonk, New York). Normal distribution of the outcome variables was confirmed for all variables. Data were analyzed in a two factor (group $\times$ time of measurement) mixed measures analysis of variance (ANOVA). When significant $F$-ratios were shown, separate one-way repeated measures ANOVA with Tukey post hoc tests were employed to determine changes across time within each trial. Separate paired Student $t$-tests were employed to determine differences between groups at each time point. A Bonferroni adjustment was performed on the unadjusted alpha value when performing multiple comparisons. For comparisons where the assumption of sphericity was violated, a Greenhouse-Geisser correction was applied. Data are presented as mean \pm standard deviation except for ordinal differentiated RPE data, which are presented as median (quartiles). Nonparametric Friedman tests and Wilcoxon signed-rank tests were used to analyze differences in ordinal differentiated RPE data during both trials. Significance was set a priori at $p \leq 0.05$. Effect sizes are presented whereby 0.2 refers to a small effect, 0.5 a moderate effect, and 0.8 a large effect according to Cohen [23].

\section{RESULTS}

The participants' peak physiological responses are shown in Table 1. A comparison between physiological responses to the HC and HYB trials is provided in Table 2. During 30 min exercise at a fixed workload $\mathrm{VO}_{2}$, percent $\dot{\mathrm{VO}}_{2 \text { peak }}$, respiratory exchange ratio (RER), and $\mathrm{BLa}^{-}$ were significantly lower in $\mathrm{HC}$ than in HYB. No difference was found between trials for $\mathrm{HR}$ or percent $\mathrm{HR}_{\text {peak }}$. 
(a)

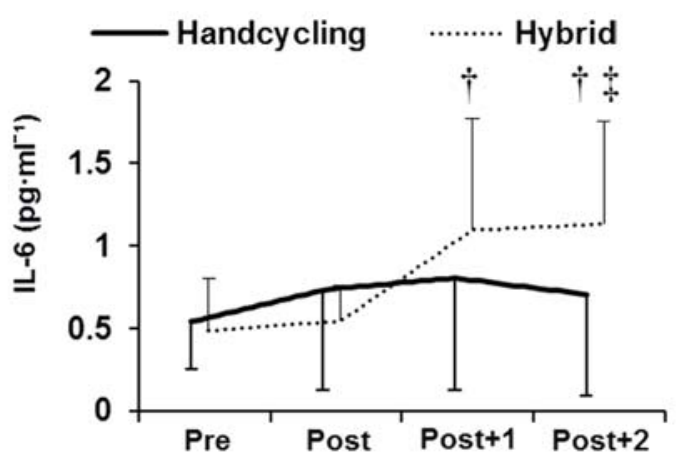

(b)

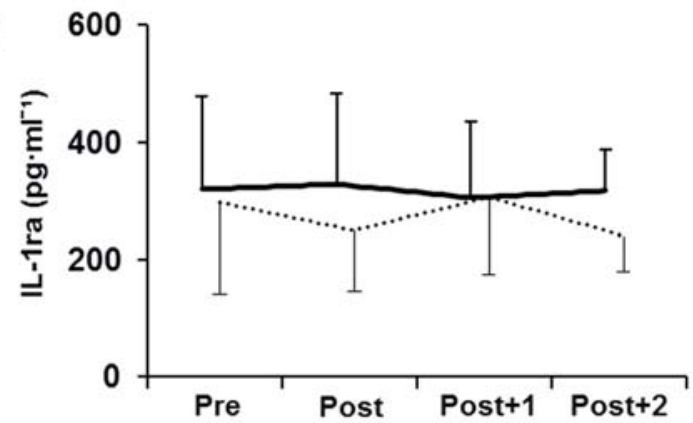

(c)

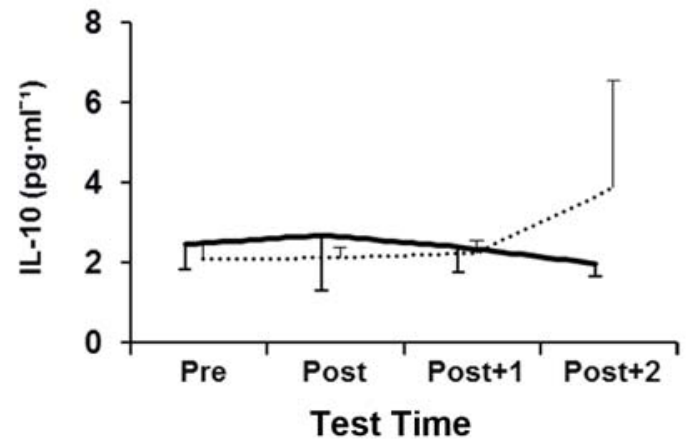

Figure 1.

Plasma cytokine responses to $30 \mathrm{~min}$ handcycling and hybrid exercise for (a) interleukin (IL)-6, (b) IL-1 receptor antagonist (IL1ra), and (c) IL-10. Data are mean \pm standard deviation. ${ }^{\dagger}$ Hybrid significantly different from pre-exercise (Pre) and postexercise (Post) $(p<0.05)$. ${ }^{\ddagger}$ Hybrid significantly different from handcycling $(p<0.05)$. Post $+1=1 \mathrm{~h}$ postexercise, Post $+2=2 \mathrm{~h}$ postexercise .

following HYB was associated with an increase in plasma IL-10 concentrations at post +2 .

The magnitude of the skeletal muscle-derived IL-6 response to acute exercise is dependent on both the intensity and duration of exercise, where intensity indirectly reflects contractile activity within the active muscle [3]. The production and release of IL-6 is regulated by a synergy of signaling pathways responsive to mechanical (a)

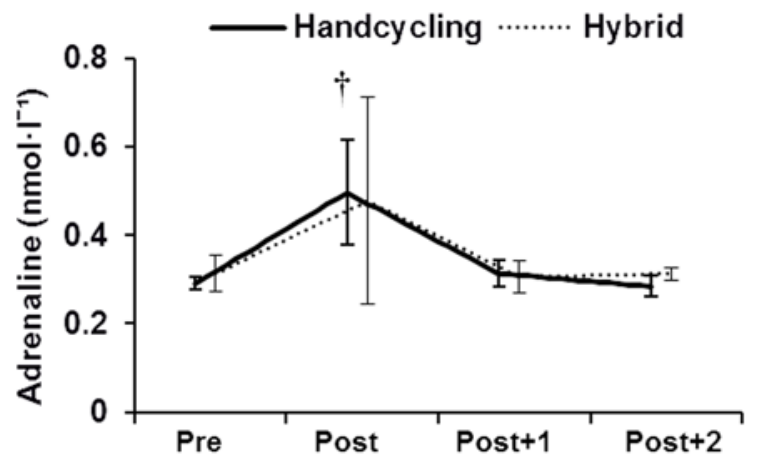

(b)

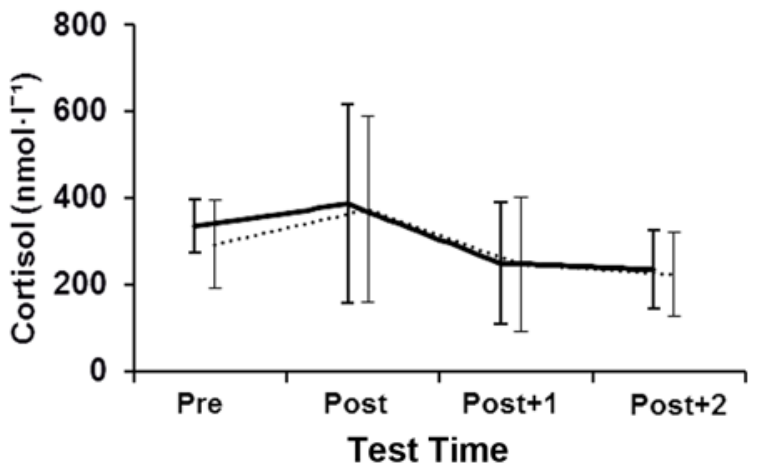

Figure 2.

Plasma (a) adrenaline and (b) cortisol responses to $30 \mathrm{~min}$ handcycling and hybrid exercise. Data are mean \pm standard deviation. ${ }^{\dagger}$ Both trials significantly different from all other time points $(p<0.05)$. Post $=$ postexercise, Post $+1=1 \mathrm{~h}$ postexercise, $\mathrm{Post}+2=2 \mathrm{~h}$ postexercise, $\mathrm{Pre}=$ pre-exercise.

stimuli, intramuscular calcium concentrations, muscle glycogen stores, and the sympathetic nervous system (SNS) $[3,12,21]$. In support of previous findings, $30 \mathrm{~min}$ of moderate intensity upper-limb exercise alone resulted in a significant increase in SNS-mediated plasma adrenaline concentrations [6-24]. Despite this SNS response, the 0.5 -fold increase in plasma IL-6 observed during $\mathrm{HC}$ was smaller than the IL-6 response previously reported by Kouda et al. in a group of non-spinal injured controls during $20 \mathrm{~min}$ arm-crank ergometry at the same relative intensity [9]. However, it must be noted that the participants in the current cohort were only recreationally active and experience of $\mathrm{HC}$ was not a prerequisite for inclusion in the study. It may therefore be suggested that the absolute PO performed $(30-50 \mathrm{~W})$ by the current untrained cohort may have been too low to initiate an IL-6 and anti-inflammatory cytokine response to $\mathrm{HC}$ alone, independent of SNS activation. 
During HC, voluntary HC drove simultaneous passive leg-cycling as the participants' feet were attached to the foot pedals to standardize limb movement and position between trials. Ter Woerds et al. previously reported no alteration in arterial leg blood flow in persons with an SCI during passive cycling [25]. It can therefore be assumed that passive movements made no contribution to the metabolic response in HC. In contrast to voluntary muscle contractions, the recruitment of motor units during electrical stimulation progresses from large motor units to small motor units [15]. The small elevation $\left(\sim 0.1 \mathrm{~L} \cdot \mathrm{min}^{-1}\right)$ in $\mathrm{VO}_{2}$ during HYB therefore represents the recruitment of highly fatigable fast-twitch muscle fibers with a low oxidative capacity [15]. The significantly greater $\mathrm{BLa}^{-}$and RER also observed during HYB highlight the reliance on anaerobic carbohydrate metabolism during FES-evoked cycling. As well as a mediator of inflammation, the myokine IL-6 is proposed as an energy sensing hormone that exerts autocrine and paracrine effects on skeletal muscle lipolysis to maintain substrate ability during exercise [3]. High rates of glucose metabolism and a subsequent lowering of muscle glycogen stores may therefore have contributed to the greater IL-6 response via stress-induced mitogen-activated protein kinase signaling, as previously described by Chan et al. [26].

In contrast to the intensity-dependent plasma antiinflammatory cytokine response reported by Scott et al. [4], no IL-1ra response was seen with either exercise mode. However, the greater IL-6 response observed following HYB was associated with a small elevation in plasma IL-10 concentrations. IL-10 is principally released by regulatory $\mathrm{T}$ cells and acts to downregulate inflammatory processes via inhibitory effects on proinflammatory cytokine expression and immune cell activation [27]. Whether the postexercise elevation following HYB was IL-6 dependent or the consequence of a blood flow and SNS-mediated elevation in circulating, IL-10 secreting immune cells requires further investigation. An interesting finding of the present study was that, in contrast to Kjaer et al. [28], SNS and hypothalamic-pituitaryadrenal (HPA)-axis activation were unaffected by the addition of FES-evoked cycling. The lack of humoral and reflex activation of the SNS and HPA-axis may be explained by the lower stimulation intensities and subsequent lower level of muscle recruitment and concentration of circulating metabolites $\left(\mathrm{BLa}^{-}=4 \mathrm{vs} 8 \mathrm{mmol} \cdot \mathrm{l}^{-1}\right)$ in the present study [28]. These findings have important implications when examining the cardiovascular responses to FES-evoked exercise.
In the current study, differentiated RPE appeared lower during $\mathrm{HYB}$ than during $\mathrm{HC}$ despite the high anaerobic component of FES-evoked cycling and the significant elevation in $\mathrm{BLa}^{-}$. This finding is in agreement with Laskin et al. who, despite a greater $\mathrm{VO}_{2}$, reported a lower overall perception of effort during hybrid rowing involving FES-evoked leg movements than arms-only rowing [29]. An increase in differentiated RPE was also observed across time during HC but not HYB in the present work. Afferent feedback relaying sensory information detailing localized chemical and mechanical stress during exercise is considered a primary driver of effort perception [30]. The accumulation of $\mathrm{H}^{+}$ions in contracting muscle is associated with lactate production during exercise, which in turn reduces muscle $\mathrm{pH}$ and induces metabolic acidosis [30]. However, afferent innervation is lost in muscle groups below the lesion level following a sensory complete SCI. The absence of change in $\mathrm{RPE}_{\mathrm{p}}$ or $\mathrm{RPE}_{\mathrm{O}}$ during HYB despite the elevated rates of lactate production and associated reduction in muscle $\mathrm{pH}$ confirms afferent feedback as primary driver of effort perception during exercise and physical stress.

The findings of this feasibility study are based on a relatively small sample size. The effect sizes observed in the physiological data were sufficient to identify significant differences between the trials. In contrast, the more variable cytokine responses may have affected the possibility of finding significant differences between trials, particularly with the IL-10 data. The magnitude of the cytokine response to FES-evoked exercise may also have been influenced by the volume of age and SCI-related skeletal muscle atrophy of the current cohort. The effect of stimulation intensity (high vs low) and mode of FESevoked contraction (cycling vs isometric) on plasma myokine and cytokine responses requires investigation in a larger cohort homogenous for age and time since injury. Emphasis should also be placed on maximizing the antiinflammatory response to voluntary upper-limb exercise, while considering the effect of relative and absolute exercise intensities on upper-limb overuse in populations with relatively low physical capacity.

\section{CONCLUSIONS}

These initial findings suggest paralyzed skeletal muscle releases the myokine IL-6 in response to electrically evoked contractions. Moderate intensity $\left(60 \% \mathrm{PO}_{\text {peak }}\right.$ obtained during $\mathrm{HC}$ only) HYB was associated with an elevation in plasma concentrations of the anti-inflamma- 
tory cytokine IL-10, an effect not present when performing HC exercise alone in an untrained cohort. HYB may offer a method of maximizing the anti-inflammatory potential of acute exercise in individuals with a thoracic SCI responsive to FES-evoked contractions. When performing voluntary upper-limb exercise alone, the absolute exercise intensity (W), as well as the relative exercise intensity $\left(\% \mathrm{PO}_{\text {peak }}\right)$, may be important in determining the magnitude of the anti-inflammatory cytokine response.

\section{ACKNOWLEDGMENTS}

\section{Author contributions:}

Study concept and design: T. A. W. Paulson, N. C. Bishop,

B. M. Smith, V. L. Goosey-Tolfrey.

Participant recruitment: T. A. W. Paulson, N. C. Bishop, B. M. Smith, V. L. Goosey-Tolfrey.

Data collection: T. A. W. Paulson.

Statistical analysis: T. A. W. Paulson, N. C. Bishop.

Drafting of manuscript: T. A. W. Paulson, N. C. Bishop, V. L.

Goosey-Tolfrey.

Critical proofreading and revision of manuscript for intellectual content: T. A. W. Paulson, N. C. Bishop, B. M. Smith, V. L. Goosey-Tolfrey.

Financial Disclosures: The authors have declared that no competing interests exist.

Funding/Support: This material is based on work supported by resources from the Peter Harrison Centre for Disability Sport at Loughborough University, a grant from The Coca-Cola Foundation to support consumable costs, and sponsorship from the Standing Start charitable foundation to cover travel costs.

Additional Contributions: The authors would like to thank Neurokinex for their support during data collection and the participants who volunteered to take part in this work. The authors would also like to acknowledge the technical support provided by Paul Moore, Rik Berkelmans, and Christof Leicht when designing the current study protocol.

Institutional Review: The authors certify that all applicable institutional and governmental regulations concerning the ethical use of human volunteers were followed during the course of this research and that all volunteers provided written informed consent to participate.

Participant Follow-Up: The authors will inform all participants upon successful publication of the study.

\section{REFERENCES}

1. Goosey-Tolfrey VL, Sutton L. Disability, chronic disease and body composition. In: Stewart A, Sutton, L, editors. Body composition in sport, exercise, and health. Abingdon (United Kingdom): Routledge; 2012. p.166-86.

2. Cowan RE, Nash MS. Cardiovascular disease, SCI and exercise: Unique risks and focused countermeasures. Dis- abil Rehabil. 2010;32(26):2228-36. [PMID:20524925]

http://dx.doi.org/10.3109/09638288.2010.491579

3. Pedersen BK. Muscular interleukin-6 and its role as an energy sensor. Med Sci Sports Exerc. 2012;44(3):392-96. [PMID:21799452]

http://dx.doi.org/10.1249/MSS.0b013e31822f94ac

4. Scott JP, Sale C, Greeves JP, Casey A, Dutton J, Fraser WD. Effect of exercise intensity on the cytokine response to an acute bout of running. Med Sci Sports Exerc. 2011; 43(12):2297-2306. [PMID:21552156] http://dx.doi.org/10.1249/MSS.0b013e31822113a9

5. Gleeson M, Bishop NC, Stensel DJ, Lindley MR, Mastana SS, Nimmo MA. The anti-inflammatory effects of exercise: Mechanisms and implications for the prevention and treatment of disease. Nat Rev Immunol. 2011;11(9):607-15.

[PMID:21818123]

http://dx.doi.org/10.1038/nri3041

6. Nash MS, Dalal KL, Martinez-Barrizonte J, Cardenas DD. Suppression of proatherogenic inflammatory cytokines as a therapeutic countermeasure to CVD risks accompanying SCI. Top Spinal Cord Inj Rehabil. 2011;16(3):14-32. http://dx.doi.org/10.1310/sci1603-14

7. Martin Ginis KA, Jorgensen S, Stapleton J. Exercise and sport for persons with a SCI. Phys Med Rehabil. 2012; 4:894-900.

8. Valent LJ, Dallmeijer A, Houdijk H, Talsma E, van der Woude L. The effects of upper body exercise on the physical capacity of people with a spinal cord injury: A systematic review. Clin Rehabil. 2007;21(4):315-30.

[PMID:17613572]

http://dx.doi.org/10.1177/0269215507073385

9. Kouda K, Furusawa K, Sugiyama H, Sumiya T, Ito T, Tajima F, Shimizu K. Does 20-min arm crank ergometer exercise increase plasma interleukin-6 in individuals with cervical spinal cord injury? Eur J Appl Physiol. 2012; 112(2):597-604. [PMID:21617884]

http://dx.doi.org/10.1007/s00421-011-2004-2

10. Umemoto Y, Furusawa K, Kouda K, Sasaki Y, Kanno N, Kojima D, Tajima F. Plasma IL-6 levels during arm exercise in persons with spinal cord injury. Spinal Cord. 2011; 49(12):1182-87. [PMID:21788952]

http://dx.doi.org/10.1038/sc.2011.74

11. Kinoshita T, Nakamura T, Umemoto Y, Kojima D, Moriki T, Mitsui T, Goto M, Ishida Y, Tajima F. Increase in interleukin-6 immediately after wheelchair basketball games in persons with spinal cord injury: Preliminary report. Spinal Cord. 2013;51(6):508-10. [PMID:23399848]

http://dx.doi.org/10.1038/sc.2013.4

12. Paulson TA, Goosey-Tolfrey VL, Lenton JP, Leicht CA, Bishop NC. Spinal cord injury level and the circulating cytokine response to strenuous exercise. Med Sci Sports Exerc. 2013;45(9):1649-55. [PMID:23475168] http://dx.doi.org/10.1249/MSS.0b013e31828f9bbb 
13. Arnet U, van Drongelen S, Scheel-Sailer A, van der Woude LH, Veeger DH. Shoulder load during synchronous handcycling and handrim wheelchair propulsion in persons with paraplegia. J Rehabil Med. 2012;44(3):222-28.

[PMID:22367531] http://dx.doi.org/10.2340/16501977-0929

14. Hettinga FJ, Valent L, Groen W, van Drongelen S, de Groot S, van der Woude LH. Hand-cycling: An active form of wheeled mobility, recreation, and sports. Phys Med Rehabil Clin N Am. 2010;21(1):127-40. [PMID:19951782] http://dx.doi.org/10.1016/j.pmr.2009.07.010

15. Ragnarsson KT. Functional electrical stimulation after spinal cord injury: Current use, therapeutic effects and future directions. Spinal Cord. 2008;46(4):255-74.

[PMID:17846639] http://dx.doi.org/10.1038/sj.sc.3102091

16. Martin R, Sadowsky C, Obst K, Meyer B, McDonald J. Functional electrical stimulation in spinal cord injury: from theory to practice. Top Spinal Cord Inj Rehabil. 2012; 18(1):28-33. [PMID:23459150] http://dx.doi.org/10.1310/sci1801-28

17. Hasnan N, Ektas N, Tanhoffer AI, Tanhoffer R, Fornusek C, Middleton JW, Husain R, Davis GM. Exercise Responses during functional electrical stimulation cycling in individuals with spinal cord injury. Med Sci Sports Exerc. 2013;45(6):1131-38. [PMID:23685444] http://dx.doi.org/10.1249/MSS.0b013e3182805d5a

18. Bakkum AJ, de Groot S, van der Woude LH, Janssen TW. The effects of hybrid cycle training in inactive people with long-term spinal cord injury: Design of a multicenter randomized controlled trial. Disabil Rehabil. 2013;35(13): 1127-32. [PMID:23061402] http://dx.doi.org/10.3109/09638288.2012.715719

19. Spungen AM, Wang J, Pierson RN Jr, Bauman WA. Soft tissue body composition differences in monozygotic twins discordant for spinal cord injury. J Appl Physiol. 2000; 88(4):1310-15. [PMID:10749824]

20. McCully KK, Mulcahy TK, Ryan TE, Zhao Q. Skeletal muscle metabolism in individuals with spinal cord injury. J Appl Physiol. 2011;111(1):143-48. [PMID:21512153] http://dx.doi.org/10.1152/japplphysiol.00094.2011

21. Welc SS, Clanton TL. The regulation of interleukin-6 implicates skeletal muscle as an integrative stress sensor and endocrine organ. Exp Physiol. 2013;98(2):359-71. [PMID:22941979] http://dx.doi.org/10.1113/expphysiol.2012.068189

22. Borg G. Borg's perceived exertion and pain scales. Champaign (IL): Human Kinetics; 1998.

23. Cohen J. A power primer. Quant Meth Psych. 1992;112(1): 155-59. [PMID:19565683] http://dx.doi.org/10.1037/0033-2909.112.1.155

24. Hooker SP, Wells CL, Manore MM, Philip SA, Martin N. Differences in epinephrine and substrate responses between arm and leg exercise. Med Sci Sports Exerc. 1990; 22(6):779-84. [PMID:2287255]

http://dx.doi.org/10.1249/00005768-199012000-00008

25. Ter Woerds W, De Groot PC, van Kuppevelt DH, Hopman MT. Passive leg movements and passive cycling do not alter arterial leg blood flow in subjects with spinal cord injury. Phys Ther. 2006;86(5):636-45. [PMID:16649888]

26. Chan MH, McGee SL, Watt MJ, Hargreaves M, Febbraio MA. Altering dietary nutrient intake that reduces glycogen content leads to phosphorylation of nuclear p38 MAP kinase in human skeletal muscle: Association with IL-6 gene transcription during contraction. FASEB J. 2004; 18(14):1785-87. [PMID:15345683]

27. Moore KW, de Waal Malefyt R, Coffman RL, O'Garra A. Interleukin-10 and the interleukin-10 receptor. Annu Rev Immunol. 2001;19(1):683-765. [PMID:11244051] http://dx.doi.org/10.1146/annurev.immunol.19.1.683

28. Kjaer M, Secher NH, Bangsbo J, Perko G, Horn A, Mohr T, Galbo H. Hormonal and metabolic responses to electrically induced cycling during epidural anesthesia in humans. J Appl Physiol. 1996;80(6):2156-62. [PMID:8806925]

29. Laskin JJ, Ashley EA, Olenik LM, Burnham R, Cumming DC, Steadward RD, Wheeler GD. Electrical stimulationassisted rowing exercise in spinal cord injured people. A pilot study. Paraplegia. 1993;31(8):534 41. [PMID:8414639] http://dx.doi.org/10.1038/sc.1993.87

30. Hampson DB, St Clair Gibson A, Lambert MI, Noakes TD. The influence of sensory cues on the perception of exertion during exercise and central regulation of exercise performance. Sports Med. 2001;31(13):935-52.

[PMID:11708402]

http://dx.doi.org/10.2165/00007256-200131130-00004

Submitted for publication August 22, 2013. Accepted in revised form December 3, 2013.

This article and any supplementary material should be cited as follows:

Paulson TA, Bishop NC, Smith BM, Goosey-Tolfrey VL. Inflammation-mediating cytokine response to acute handcycling exercise with/without functional electrical stimulation-evoked lower-limb cycling. J Rehabil Res Dev. 2014;51(4):645-54.

http://dx.doi.org/10.1682/JRRD.2013.08.0184

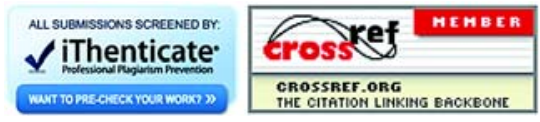


